\title{
Short and long-lived radium isotopes in surface waters from Ilha Grande bay, Angra dos Reis, Brazil
}

\author{
F.C. Gomes ${ }^{1}$, J.M. Godoy ${ }^{2,3}$, Z.L. Carvalho² and R.T. Lopes ${ }^{1}$ \\ ${ }^{1}$ Programa de Engenharia Nuclear, COPPE/UFRJ, Cidade Universitária, \\ Caixa Postal 68.509, 21945-970 Rio de Janeiro, Brazil \\ ${ }^{2}$ Instituto de Radioproteção e Dosimetria (IRD), Caixa Postal 37750, Barra da Tijuca, \\ 22642-970 Rio de Janeiro, Brazil \\ ${ }^{3}$ Departamento de Química, Pontifícia Universidade Católica do Rio de Janeiro (PUC-Rio), \\ Rua Marquês de São Vicente 225, 22453-900 Rio de Janeiro, Brazil
}

\begin{abstract}
The Angra dos Reis nuclear power plant site is located $130 \mathrm{~km}$ south from Rio de Janeiro city. Seawater is used as cooling water for both units; the cooling water is pumped from Itaorna Bay and discharged into Piraquara de Fora Bay, together with the liquid effluents from the two NPPs. Piraquara de Fora Bay belongs to a large bay system, Ilha Grande Bay and, therefore, conservative radionuclides in seawater will reach this bay with the tidal movement and, at the end, exported to open sea. Radium isotopes behave conservatively in seawater and can be applied as natural tracers to carry out dispersion studies. Two transets involving eight sampling points each were performed in Ilha Grande bay and ${ }^{228} \mathrm{Ra}$, ${ }^{226} \mathrm{Ra},{ }^{224} \mathrm{Ra}$ and ${ }^{223} \mathrm{Ra}$ determination realized. The results have shown that the conservative radionuclide dispersion is controlled by eddy diffusion with negligible net offshore advection. The calculated eddy diffusion coefficient was $26 \mathrm{~km}^{2} \cdot \mathrm{d}^{-1}$ and $25 \mathrm{~km}^{2} \cdot \mathrm{d}^{-1}$, based on ${ }^{223} \mathrm{Ra}$ and ${ }^{224} \mathrm{Ra}$ respectively.
\end{abstract}

\section{INTRODUCTION}

The Angra dos Reis nuclear power plant site is located $130 \mathrm{~km}$ south from Rio de Janeiro city. There are two pressured water reactors in operation at the site: the first one started operation in 1985 and has a nominal capacity of 660 MWe and the second one is a 1300 MWe unit and started its operation in 2000. Seawater is used as cooling water for both units; the cooling water is pumped from Itaorna Bay and discharged into Piraquara de Fora Bay, together with the liquid effluents from the two NPP. Piraquara de Fora Bay belongs to a large bay system, Ilha Grande Bay, and therefore, conservative radionuclides in seawater will reach this bay with the tidal movement and, at the end, exported to open sea.

Dispersion of discharged radionuclides was modeled by Franklin [1] in order to allow the assessment of the committed dose incurred by the local population in case of normal operation and accidents. The results obtained suggested that conservative radionuclides released, such as ${ }^{137} \mathrm{Cs}$ and ${ }^{3} \mathrm{H}$, are efficiently exported to the open ocean.

In order to validate this model, it was first thought to use the released tritium as a tracer. However, its potential application was restricted to the Piraquara de Fora Bay. For a longer distance an alternative was needed. With the development of the research papers related to the importance of the submarine groundwater discharge (SGD) as an relevant source of substances to the coastal region and, in particular, with the consequent use of radium isotopes for the determination of coastal mixing rates [2], it was decided to investigate its potential application as a way to validate the dispersion model.

The variation of the concentration or activity (a) of a non-reactive and conservative tracer along the time $(t)$ and in function of in the distance $(x)$, having the coastal margin as referential, can be express as a dynamic balance between eddy diffusion and advection (eq. (1)), where $K_{h}$ is the coefficient of eddy diffusion and $w$ is the advective velocity. If the offshore distribution is dominated by diffusion with constant $\mathrm{Kh}$, a plot of activity vs. distance will be a straight line connecting the end members. 
Offshore advection will cause positive curvature and onshore advection will cause negative curvature to this plot [2].

$$
\frac{d A}{d t}=K_{h} \frac{\partial^{2} A}{\partial x^{2}}-\omega \frac{\partial A}{\partial x^{\prime}}
$$

However, the use of short-lived radionuclides requires an additional term related to its decay (eq. (2)):

$$
\frac{d A}{d t}=K_{h} \frac{\partial^{2} A}{\partial x^{2}}-\omega \frac{\partial A}{\partial x^{\prime}}-\lambda A
$$

In the specific case of the Ilha Grande Bay, it was concluded that the distribution of isotopes is predominantly controlled by diffusive effects [1] being possible, therefore, to reject the liquid advection. In consequence of this fact, for short half-lives of ${ }^{223} \mathrm{Ra}$ and ${ }^{224} \mathrm{Ra}$, the previous equation can be simplified; being omitted the component of the advection (eq. (3)):

$$
\frac{d A}{d t}=K_{h} \frac{\partial^{2} A}{\partial x^{2}}-\lambda A
$$

Based on the hypothesis that $K_{h}$ presents a constant value and that the system is submitted to a steadystate condition, it is feasible the estimate of $\mathrm{K}_{\mathrm{h}}$ based on a graph of $\ln { }^{223} \mathrm{Ra}$ (or the ${ }^{224} \mathrm{Ra}$ ) with the distance $x$ (eq. (4)).

$$
\ln A_{x}=\ln A_{0}-x \sqrt{\frac{\lambda}{K_{h}}}
$$

In this case, the slope $m$ is equal to:

$$
m=\sqrt{\frac{\lambda}{K_{h}}} .
$$

\section{MATERIALS AND METHODS}

Two transects were carried out with 10 sampling points each one (Figure 1). At each one about 200 liters were taken, the water samples were processed into Mn coated acrylic fiber columns, being the radium quantitatively extracted [3].

The ${ }^{223} \mathrm{Ra}$ and ${ }^{224} \mathrm{Ra}$ activities were determined by means of a closed circulation system as described by Moore and Arnold [4], comprising a helium flow through the manganese fiber to remove ${ }^{219} \mathrm{Rn}$ and ${ }^{220} \mathrm{Rn}$ generated by both ${ }^{223} \mathrm{Ra}$ and ${ }^{224} \mathrm{Ra}$ decay. The gas flow containing the radon isotopes cross a Lucas cell, in which the alpha particles are supposed to be captured by an enclosed tube photo-multiplier (TFM). The generated pulses by TFM were then driven to a delayed coincidence system like the one adopted by Giffin et al. [5] and adapted for radium measurements by Moore and Arnold [4]. In order to identify the alpha particles and thus to determine the activities of the retained ${ }^{223} \mathrm{Ra}$ and ${ }^{224} \mathrm{Ra}$ in the manganese fiber, the delayed coincidence system is based on the decay of the polonium short half-life isotopes and the ${ }^{219} \mathrm{Rn}$ and ${ }^{220} \mathrm{Rn}$. Three measurements are performed with each sample, one shortly after sampling for ${ }^{224} \mathrm{Ra}$ determination, a second one about 10 days after for ${ }^{223} \mathrm{Ra}$ and the last one four weeks later in order to determine ${ }^{228} \mathrm{Th}$, used for correct the ${ }^{224} \mathrm{Ra}$ concentration.

After the ${ }^{228} \mathrm{Th}$ determination, the manganese dioxide was dissolved using hydrochloridric acid and hydroxylamine hydrochloride. ${ }^{226} \mathrm{Ra}$ and ${ }^{228} \mathrm{Ra}$ were co-precipitate with $\mathrm{BaSO}_{4}$ and $\mathrm{PbSO}_{4}$ and determined by alpha and beta counting, after chemical purification, as described by Godoy et al. [6].

At each sampling site, a $100 \mathrm{~mL}$ sample was taken and kept frozen the determination of salinity, silica and barium. Barium and silica were determination by inductively coupled plasma atomic emission spectrometry (Perkin-Elmer ICP-AES Optima 2000 DV), salinity by conductivity measurement. 


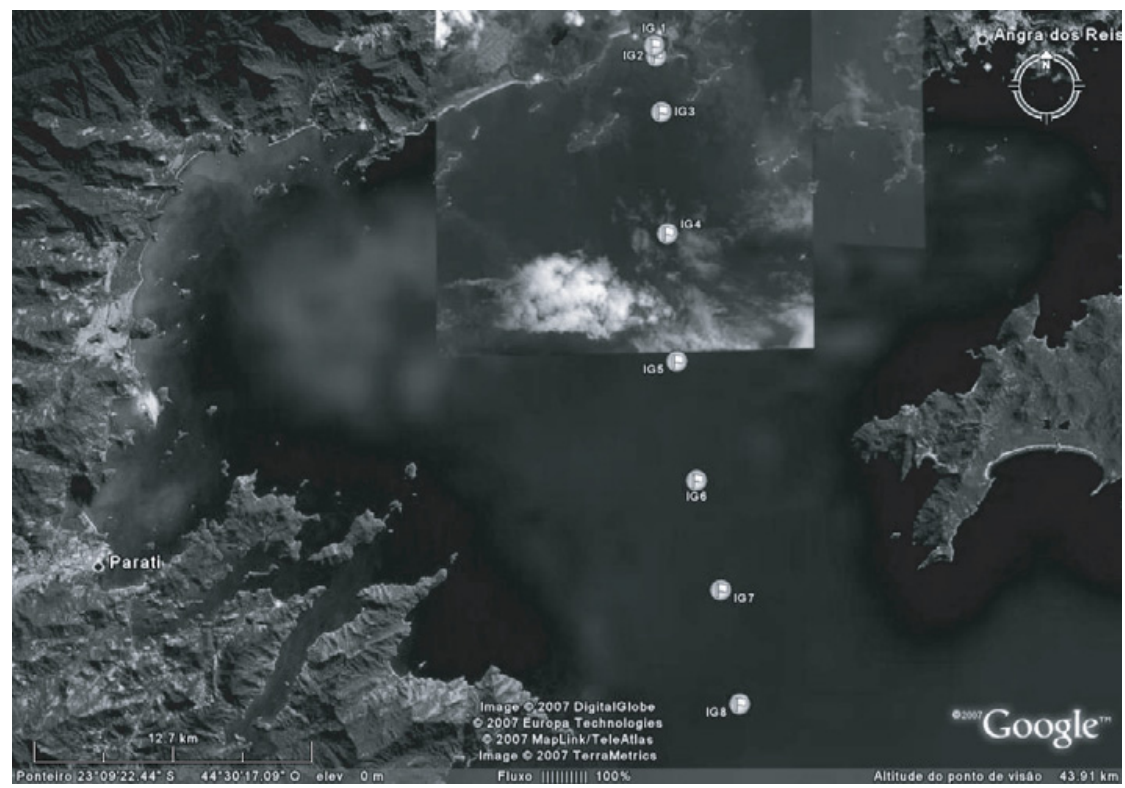

Figure 1. Surface seawater sampling points in Ilha Grande Bay.

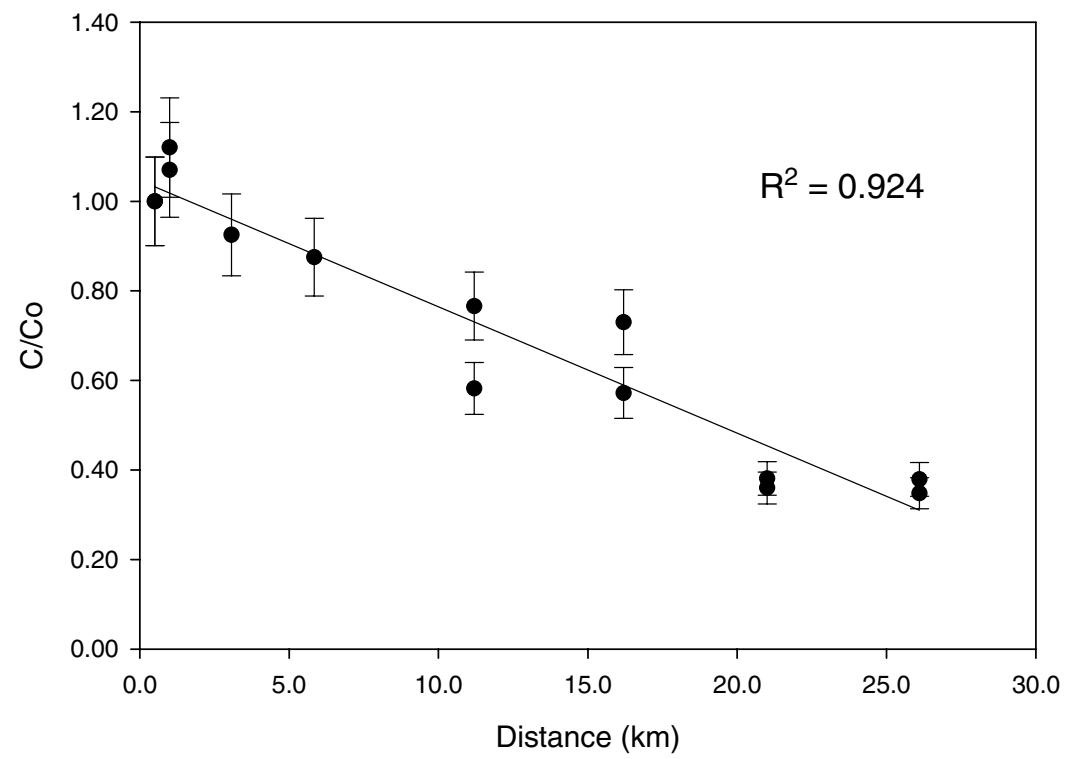

Figure 2. Profile of the ${ }^{228} \mathrm{Ra}$ concentration as a function of the distance offshore.

\section{RESULTS AND DISCUSSION}

Figure 2 shows the ${ }^{228} \mathrm{Ra}$ concentration change with the distance to the shoreline, the concentrations were normalized to the ${ }^{228} \mathrm{Ra}$ concentration in the first sample in order to take into account the submarine groundwater discharge fluctuation with the tide level from one sampling day to the other. The obtained 
straight line validates the hypothesis the dispersion of conservative tracers in Ilha Grande Bay is dominated by eddy diffusion.

The ${ }^{223} \mathrm{Ra}$ and ${ }^{224} \mathrm{Ra}$ concentrations plotted as a function of distance offshore are shown in Fig. 3. Both these short-lived tracers have high concentrations near the coast and decrease significantly to the open-ocean. For ${ }^{223} \mathrm{Ra}$ and ${ }^{224} \mathrm{Ra}$, the data, within this region, fit an exponential decay with an angular coefficient of $-0.0210\left(\mathrm{R}^{2}=0.902\right)$ and $-0.0380\left(\mathrm{R}^{2}=0.920\right)$ for ${ }^{223} \mathrm{Ra}$ and ${ }^{224} \mathrm{Ra}$, respectively. These curves can be taken as strong evidence that the distributions are controlled by eddy diffusion with negligible net offshore advection. Using eq. (5) and its assumptions, the value of $\mathrm{K}_{\mathrm{h}}$ derived from ${ }^{223} \mathrm{Ra}$ is $26 \mathrm{~km}^{2} \cdot \mathrm{d}^{-1}$ and for ${ }^{224} \mathrm{Ra}$ yields $\mathrm{K}_{\mathrm{h}}$ equal to $25 \mathrm{~km}^{2} \cdot \mathrm{d}^{-1}$.

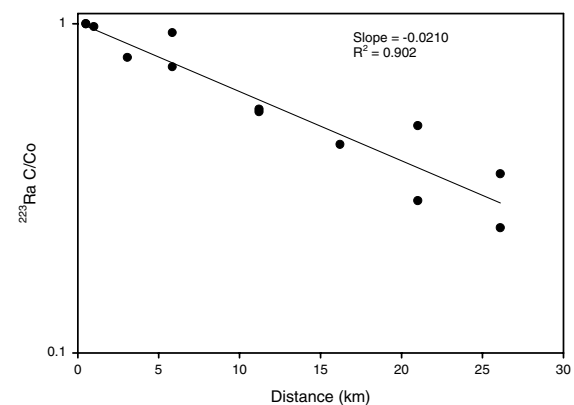

a)

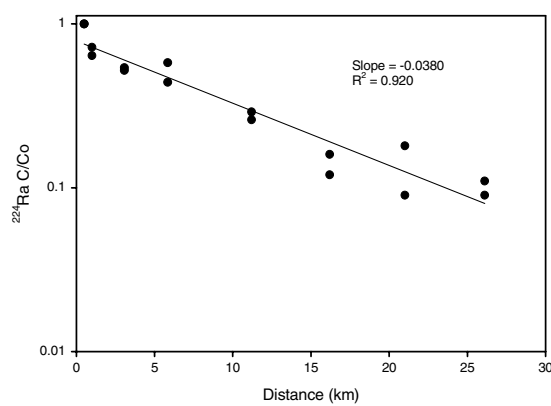

b)

Figure 3. Profile of the ${ }^{223} \mathrm{Ra}$ (a) and ${ }^{224} \mathrm{Ra}$ (b) concentration as a function of the distance offshore.

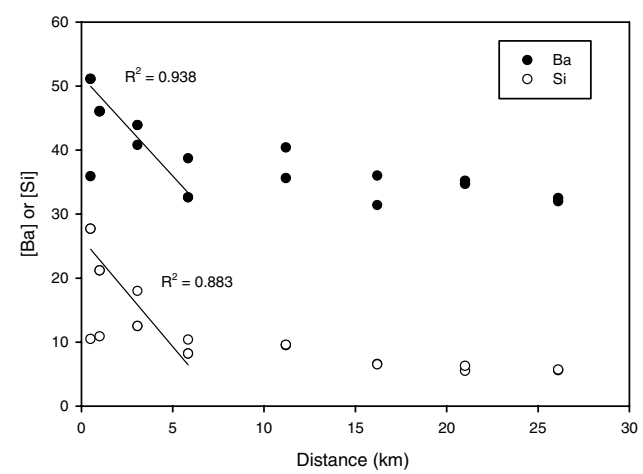

(a)

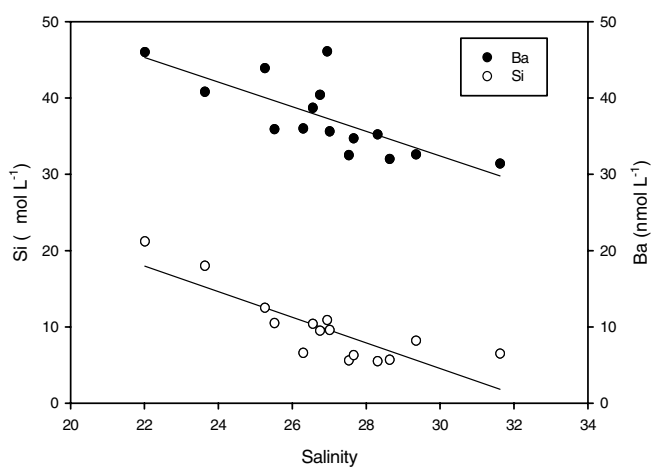

(b)

Figure 4. Profile of $\mathrm{Ba}$ and $\mathrm{Si}$ as a function of distance offshore (a) and Salinity (b).

The barium and silica concentrations plotted as a function of distance offshore (a) as well as a function of salinity (b) are shown in Fig. 4. The spatial trends noted in Fig. 3 are also evident here. The barium and silica concentrations decrease within $5.8 \mathrm{~km}$ and fit a line with $\mathrm{R}^{2}=0.938$ and 0.883 , respectively, and reach a relatively constant value at distances of $5.8-26.1 \mathrm{~km}$ of the coast. In addition, there are two breaks in the slope at $11.2 \mathrm{~km}$ and another at $21.0 \mathrm{~km}$. These two breaks could be due to the existence of Ilha Grande submarine groundwater discharge (SGD) and a current flowing through the Ilha Grande/Angra dos Reis channel.

Salinity, Ra isotopes, barium and silica concentrations show large spatial variations in Ilha Grande Bay. Salinity in surface seawater range from 22 to 32 psu, with the lowest in the innermost bay (Fig. 4b). 
The concentrations of barium, silica and radium isotopes are higher in the inner part of the bay (Figs. 2, 3 and $4 \mathrm{a}$ ), indicating similar sources from lower salinity waters.

\section{CONCLUSIONS}

The results have shown that the shoreline supply of radium through submarine groundwater discharge in Ilha Grande is such that it can be used as a tracer for the determination of coastal mixing rates and, consequently, be applied as a tool for the validation of the existing marine dispersion model for this site. However, due to the potential influence of two others radium sources, Ilha Grande SGD and the current flowing through the Ilha Grande/Angra dos Reis channel, additional SGD tracers as short-lived radium isotopes, silica and barium will be useful.

\section{Acknowledgment}

The authors would like to thank the Conselho Nacional de Desenvolvimento Científico e Tecnológico (CNPq) for the financial support, Electronuclear to allows us to use its laboratory at the reactor site and the Comissão Nacional de Energia Nuclear for Ms. Gomes grants.

\section{References}

[1] Franklin, M.R., Estudo da Circulação Hidrodinâmica e do Transporte de Radionuclideos na Baía da Ilha Grande - RJ, Master Thesis., Departamento de Engenharia Civil, COPPE/UFRJ, Rio de Janeiro, RJ, Brazil, 2001.

[2] Moore, W.S., Continental Shelf Research 20, 2000, 1993-2007

[3] Moore, W.S., Deep-Sea Research and Oceanographic Abstracts 23, 1976, 647-651

[4] Moore, W.S., Arnold, R., Journal of Geophysical Research 101, 1996, 1321-1329

[5] Giffin, C. Kaufman, A. and Broecker, W., Journal of Geophysical Research 68, 1963, 1749-1757.

[6] Godoy, J.M., Lauria, D.C., Godoy, M.L.D.P. and Carvalho, Z.L., Journal of Radioanalytical and Nuclear Chemistry 182, 1984, 165-169. 
